\title{
Isobaric Vapor Liquid Equilibrium Determination for 1,3,5-Trimethylbenzene + Ethanol and 1,3,5-Trimethylbenzene + n-Butanol Binary Systems
}

\author{
Marilena Nicolae ${ }^{1 *}$, Costin Sorin Bîldea² \\ ${ }^{1}$ Petroleum Processing and Environmental Engineering Department, Faculty Petroleum Technology and Petrochemistry, \\ Petroleum-Gas University of Ploiesti, 39 Bucuresti Blvd., 100680 Ploiesti, Romania \\ 2 Department of Chemical and Biochemical Engineering, Faculty of Applied Chemistry and Materials Science, University \\ Politehnica of Bucharest, 1-7 Gheorghe Polizu St., sector 1, 011061 Bucharest, Romania \\ * Corresponding author, e-mail: nicolae_marilena@yahoo.com
}

Received: 07 June 2019, Accepted: 26 August 2019, Published online: 30 October 2019

\begin{abstract}
The vapor-liquid equilibrium data are necessary for the design of the distillation columns which separate the mixture mesitylene $A B E$ components resulting from the liquid-liquid extraction of butanol from the ABE using 1,3,5-trimethylbenzene as solvent. In this work, the vapor - liquid equilibrium data is determined for the binary systems: ethanol + 1,3,5-trimethylbenzene and n-butanol + 1,3,5-trimethylbenzene at constant pressure of $93.325 \mathrm{KPa}$ using a double phase circulation apparatus. Thus, P-T-x-y data is determined, which is further processed by regression to determine the binary interaction parameters of the NRTL and UNIQUAC models. Furthermore, the T-x-y diagrams are calculated using the completed thermodynamic models (NRTL and UNIQUAC) and the UNIFAC predictive model, and compared with the experimental diagrams.
\end{abstract}

Keywords

mesitylene, n-butanol, ethanol, VLE, NRTL, UNIQUAC

\section{Introduction}

n-Butanol has been proved to be a superior alternative to ethanol as additive for fossil fuels used in the internal combustion engines (ICE). Butanol is compatible with the ICE, it is less flammable than gasoline and is miscible with gasoline in any proportion, these properties leading to the statement that butanol can be added to gasoline in the early stage, before storage and distribution [1]. $\mathrm{n}$-Butanol is above ethanol in terms of net heat of combustion (NHOC). The NHOC of butanol is $29.2 \mathrm{MJ} / \mathrm{L}$, which represents $83 \%$ from $\mathrm{NHOC}$ of the gasoline $(32.5 \mathrm{MJ} / \mathrm{L})$. Ethanol has an NHOC of $21.13 \mathrm{MJ} / \mathrm{L}$, while methanol develops 14.63 MJ/L through combustion [2]. But n-butanol has more advantages than ethanol: it is less hygroscopic, is safer than ethanol, considering that the butanol has a smaller vapor pressure and a higher flash point than the ethanol. Butanol can be considered an ideal alternative to other biofuels used until now.

n-Butanol can be obtained through hydrogenation of crotonaldehyde (obtained by condensation of two molecules of acetaldehyde) or by hydroformylation of propylene to butyraldehyde followed by catalytic hydrogenation (process from which a mixture of iso-butanol and n-butanol is obtained). These chemical methods imply the utilization of raw materials coming from non-renewable sources. n-Butanol can be also obtained from bioresources, through fermentation using Clostridium strains (Clostridium acetobutylicum, Clostridium beijerinckii, Clostridium saccharoperbutylacetonicum, Clostridium saccharobutylicum) [3-7]. In this case, n-butanol is obtained as a mixture of water, acetone, n-butanol, and ethanol, commonly named ABE. The concentration of butanol in the ABE mixture is low, under $4 \mathrm{mass} \%$. On the other side, water forms a heteroazeotrope with butanol with minimum boiling temperature and a homogenous azeotrope with ethanol. This fact makes the separation of the ABE mixture a task which is difficult to achieve by conventional distillation.

Biobutanol is not yet used on large scale as fuel or fuel additive due to the difficult separation from the ABE mixture, which requires large amounts of energy and costly 
equipment. Separation of butanol through conventional distillation needs $18.4 \mathrm{MJ} / \mathrm{kg}$, which represents $54 \%$ of the energy developed by combustion of $1 \mathrm{~kg}$ butanol [8]. Therefore, the separation of butanol from the ABE mixture through simple distillation is not a feasible option from an economic point of view. On the other side, the toxicity of acetone and butanol on Clostridium strain requires the removal of fermentation products at certain key moments, when their concentration in the broth still does not affect the Clostridium strain. This means that the proportion of water in the broth is large. The separation of the mixture by distillation involves the vaporization of this large amount of water, a fact that can be translated in large energy requirements in the reboilers. To save energy, other techniques as gas stripping, adsorption, pervaporation and liquid-liquid extraction can be combined with distillation in complex schemes in order to increase the concentration of the ABE mixture.

Gas stripping is a method that can be used to remove the $\mathrm{ABE}$ compounds in situ. It implies the utilization of an inert gas as $\mathrm{H}_{2}$ or $\mathrm{CO}_{2}$ for the stripping of acetone, butanol and ethanol from the fermentation broth. This method has the advantage that can be applied in situ [9]. The fermenting gas (a mixture of $\mathrm{CO}_{2}$ and $\mathrm{H}_{2},[10,11]$ ), an inert gas $\left(\mathrm{CO}_{2}[2]\right.$ or $\left.\mathrm{N}_{2}[12]\right)$, or a mixture of inert gases $\left(\mathrm{CO}_{2}\right.$, $\mathrm{N}_{2}, \mathrm{H}_{2},[13]$ ) can be used as stripping agent.

Pervaporation combined with distillation is another alternative to separate butanol from the ABE mixture. When a hydrophobic membrane is contacted with the ABE liquid mixture, acetone, butanol and ethanol pass through the membrane, which helps breaking the ethanol-water and butanol-water azeotropes. Pervaporation owns the advantages of a low energy requirement, it does not affect microorganisms, while losses of nutrients and substrates are prevented. Pervaporation is particularly promising for separating azeotropic mixtures with close boiling points since the separation is dependent on the solubility/ sorption and diffusivity of components rather than their volatility [14]. Numerous researches related to the separation of butanol by pervaporation have been performed, among which we mention Li et al. [15], Qureshi et al. [16] and Lipnizki et al. [17].

Adsorption, along with pervaporation and liquid-liquid extraction, is considered one of the most economical processes for separating butanol from the ABE mixture. When this technique is applied, butanol adsorbs on the surface of a solid adsorbent, and then is removed from by a desorption process consisting either in the gradual heating of the adsorbent or in the displacement of the molecules of adsorbed butanol. In both cases concentrated solutions of butanol are obtained. Adsorption capacity, selectivity and ease of desorption are essential factors to consider when choosing an adsorbent. Numerous studies on the adsorption of butanol on different adsorbents have been carried out, but few of them also address the reverse butanol desorption process and the adsorbent reuse. Various materials such as active carbon [18], polymer resins [19] or zeolites [20] may be used as adsorbents.

Liquid-liquid extraction, as mentioned above, is considered to be one of the most economical butanol separation processes if the extraction solvent used has good selectivity for butanol and is readily regenerable. Liquid-liquid extraction, followed by distillation, is one of the processes that are highly likely to be used to separate butanol. Liquid-liquid extraction applied to ABE separation has been studied in several papers [21-28]. A good extraction solvent should have a high solubilization capacity, high selectivity towards butanol, a boiling temperature different from that of butanol and of the other solubilized components. It is also very important that the solvent does not form an azeotrope with the solubilized compounds and have a small latent evaporation heat.

Oleyl alcohol is one of the most well-known solvents for liquid-liquid extraction of butanol in ABE. There are several papers presenting the results of the research on this solvent, whether used as such [21-23] or together with a co-solvent. Oleyl alcohol has the advantage of having low toxicity on Clostridium bacteria. Other solvents that may be used for butanol extraction are higher alcohols such as hexanol [24], heptanol, octanol [22, 23], but these alcohols are toxic to Clostridium bacteria, although they have a good solvating capacity. Another alcohol proposed and studied for butanol extraction is 2-ethyl hexanol [25]. In 2010, Kraemer [26] conducted a scan of the properties of certain compound (alcohols and alkanes) using CAMD (computer-aided molecular design) to determine the compatibility of butanol with these compounds in order to find a suitable solvent for the butanol extraction. Thus, it was found that 1,3,5-trimethylbenzene (mesitylene) is a good solvent for the extraction of butanol from $\mathrm{ABE}$, as it has a very high selectivity (2500-4300) towards butanol in the presence of water [26]. On the other hand, an experimental study [27] of the liquid-liquid equilibrium in the water-mesitylene-butanol ternary system confirmed that the mesitylene selectivity towards butanol is much higher than the mesitylene selectivity towards the water. 
Liquid-liquid extraction processes with mesitylene [26-28] have even been proposed.

We have noticed that the UNIFAC predictive model was used to assess the use of mesitylene as a solvent for different process schemes based on liquid-liquid extraction. However, the vapor-liquid equilibrium of the n-butanol/ mesitylene and ethanol/mesitylene mixtures, required to design the solvent recovery column, is better predicted by thermodynamic model with parameters determined from experimental data, such as NRTL or UNIQUAC. To the best of our knowledge, binary interaction parameters of the NRTL or UNIQUAC models specific to the mesitylene $+\mathrm{n}$-butanol are missing from the literature. Following experiments performed in the laboratory, we found that mesitylene is completely miscible with n-butanol, ethanol and with acetone. This paper aims to present vapor-liquid equilibrium data for n-butanol + mesitylene and for ethanol + mesitylene mixtures, determined at constant pressure, and to determine the binary interaction parameters of the NRTL and UNIQUAC thermodynamic models.

\section{Experimental}

\subsection{Materials}

The vapor-liquid equilibrium (P-T-x-y data) for the binary mixtures n-butanol + mesitylene and ethanol + mesitylene is determined at constant pressure of $93.33 \mathrm{kPa}$. The composition of the initial mixtures is varied from 0 up to 1 alcohol mole fraction. The apparatus and the procedure are explained below.

The chemicals used in the experimental and their properties are presented in Table 1. All chemicals were used with no further purification.

\subsection{Apparatus and procedure}

The apparatus for determining the vapor-liquid equilibrium is shown in Fig. 1. It is produced by NORMAG Labor und Prozesstechnik GmbH and consists of a compactly built, highly sophisticated body of borosilicate glass.

Table 1 Materials used in the experimental [29-31]

\begin{tabular}{lccc}
\hline Component name & Source & $n_{D}^{20}$ & $\begin{array}{c}\text { Purity/mass } \\
\text { fraction }\end{array}$ \\
\hline Ethanol & $\begin{array}{c}\text { Chemical } \\
\text { Company } \\
\text { n-Butanol }\end{array}$ & $1.3610^{[29]}$ & 0.993 \\
Sigma & $1.3990^{[30]}$ & 0.995 \\
Aldrich & $\begin{array}{c}\text { Sigma } \\
\text { Aldrich }\end{array}$ & $1.4990^{[31]}$ & 0.98 \\
\hline
\end{tabular}

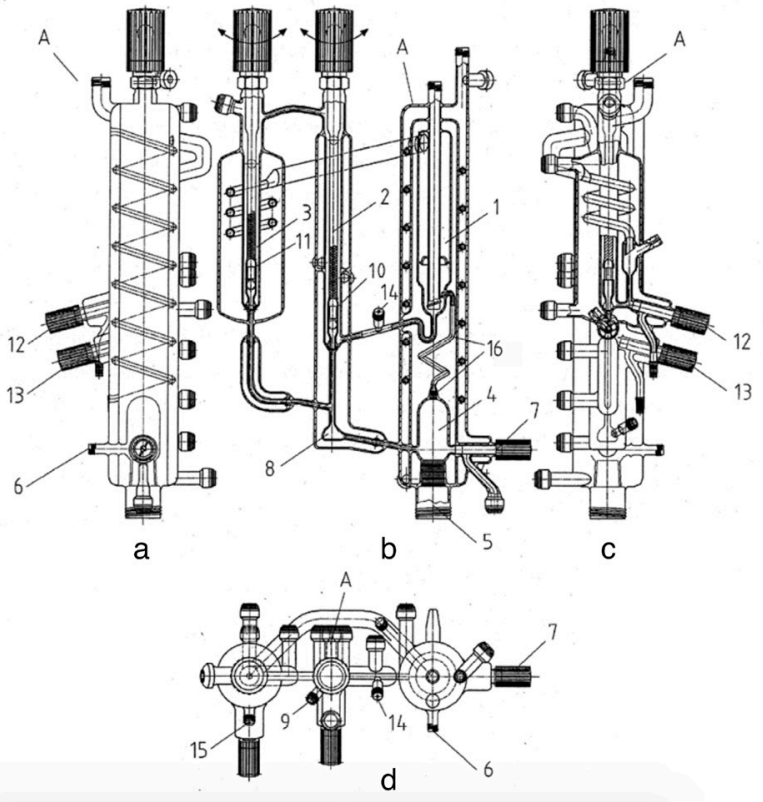

Fig. 1 Vapor-liquid equilibrium body of apparatus for determining vapor-liquid equilibrium: a-view from right; b-front view; c-view from left; d-view from above; 1-vapor-liquid equilibrium section; 2-liquid return; 3-condensate return; 4-vapor-liquid equilibrium vessel; 5-quartz-rod immersion heater; 6-threaded opening of the vapor-liquid equilibrium vessel; 7-drain valve of the vapor-liquid equilibrium section; 8-mixing chamber; 9-threaded opening for the mixing chamber; 10 -valve tappet guided from above for the liquid return; 11-valve tappet guided from above for the liquid return; 12-sampling valve for vapor return; 13-sampling valve for liquid return; 14-capillary thread with insertion septa for small quantity liquid sample; 15-capillary thread with insertion septa for small quantity of condensed vapor sample; 16-Cotrell pump

The front view (Fig. 1b) shows on the right side the vapor-liquid equilibrium section (1) with an inner high-vacuum-insulated jacket and an outer temperature-stabilized jacket for separating the vapor from the liquid phase, in the middle the liquid return (2) and on the outer left the condensate return (3). Both return sections are provided with temperature-stabilized jackets, which can be cooled or kept at a given temperature with a heating/cooling thermostat.

The vapor-liquid equilibrium vessel (4) is heated by means of an internally situated quartz-rod immersion heater (5), whose heating power can be adjusted. The surface of the quartz-rod immersion heater is rough and thereby promotes the formation of boiling bubbles. If this is not sufficient, boiling chips made from e.g. PTFE can be introduced via the threaded opening (6). The vapor-liquid equilibrium section (1) incorporates a drain valve (7) for the liquid mixture and a thread (6) for introducing an air leak 
tube. The liquid return (2) and the condensate return (3) end in a mixing chamber (8), in which a stirring bar can be introduced via a threaded opening (9) in order to achieve sufficiently thorough mixing with a small magnetic stirrer.

The liquid return (2) and the condensate return (3) can be closed via the manually operated glass valve tappets guided from above $(10+11)$ and thereby stemmed so that larger samples can be easily drawn off via the sampling valves $(12+13)$. Both the liquid return and the vapor-condensate return are provided with capillary threads $(14+15)$ with insertion septa for small sample quantities.

The temperature in the equilibrium cell is measured with $\mathrm{Pt} 100$ digital thermometer (measuring range $-20^{\circ}$ to $+200{ }^{\circ} \mathrm{C}$, reading accuracy $0.01{ }^{\circ} \mathrm{C}$ ). The temperature in the external heating jacket is maintained with a Julabo heating thermostat (operating range $+20^{\circ}$ to $+200{ }^{\circ} \mathrm{C}$ ).

\subsection{Procedure}

A mixture of $70 \mathrm{~cm}^{3}$ consisting of ethanol and mesitylene (respectively butanol and mesitylene) was introduced in the apparatus through the thread (15). The whole system was coupled to the vacuum pump to maintain the pressure at $93.33 \mathrm{kPa}$ (the operating pressure in the experiments) and gradually heated. As a result of the action of the Cotrell pump at the top end of the liquid-filled vapor-liquid equilibrium vessel, vapor bubbles and liquid droplets are delivered into the vapor space. In the process they separate without condensate and evaporative losses and generate a circulation of the liquid phase and the separated vapor condensate back into the vapor-liquid equilibrium vessel. They are mixed with each other again in the mixing chamber and forced by convection in the vapor-liquid equilibrium vessel to the boiling surface, at which they boil again. After a period, the mixture reaches the state of equilibrium, in which the vapor and liquid phases are found at the exact boiling temperature at the working pressure. The vapor and liquid phases in equilibrium can be clearly characterized by the concentration of the two components. The composition of the phases can be determined by sampling and analysis by GC or refractive index method. The samples are taken simultaneously, 30 minutes after reaching of the equilibrium state, when no variation of the temperature in the equilibrium cell and no variation of the pressure is observed. This procedure was performed for each binary mixture. 8 ethanol + mesitylene mixtures and 8 butanol + mesitylene mixtures with different concentrations were considered, covering the whole composition range (from 0 to 1 ethanol mole fraction, respectively from 0 to 1 butanol mole fraction). The samples taken during experiments were analyzed and the results are presented in the Section 3.

\section{Experimental results}

The composition of the samples was determined by measuring the refractive index (with a Carl Zeiss Abbe Refractometer Type 6), after determining a calibration curve for each binary mixture. The pairs refractive indexes - known composition of the mixtures are displayed in Table 2. The values from Table 2 were used to plot the calibration curves displayed in Fig. 2 and Fig. 3.

Fig. 2 and Fig. 3 also display the fitted curves (red line) obtained by the regression of the values from Table 2 .

The regression of the data sets refractive indexes - composition (expressed in mole $\%$ of ethanol), for the mixture ethanol + mesitylene lead to the Eq. (1) which describes the mathematical correlation between composition and refractive index. For this correlation $R_{a d j}^{2}=0.99998$.

Table 2 Refractive indexes of the samples prepared for the calibration curves for the binary mixtures: ethanol + mesitylene and n-butanol + mesitylene

\begin{tabular}{cccc}
\hline \multicolumn{2}{c}{ Ethanol + mesitylene } & \multicolumn{2}{c}{ n-Butanol + mesitylene } \\
mole \% ethanol & $n_{D}^{20}$ & mole \% butanol & $n_{D}^{20}$ \\
\hline 0 & 1.4992 & 0 & 1.4992 \\
31.47 & 1.4770 & 31.34 & 1.4744 \\
47.89 & 1.4599 & 43.24 & 1.4647 \\
56.69 & 1.4490 & 62.58 & 1.4460 \\
73.97 & 1.4230 & 67.86 & 1.4402 \\
82.69 & 1.4060 & 73.28 & 1.4335 \\
92.13 & 1.3840 & 80.12 & 1.4255 \\
100 & 1.3625 & 100 & 1.3995 \\
\hline
\end{tabular}

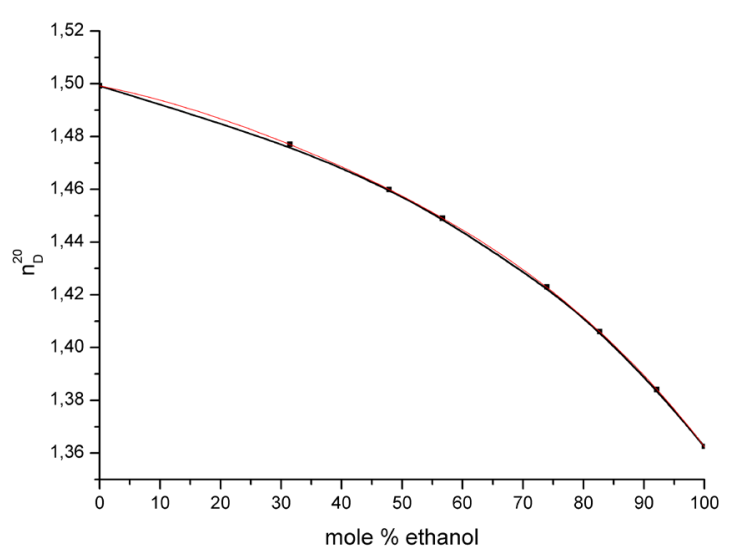

Fig. 2 Variation of refractive index with the composition (as mole \% ethanol) used as calibration curve for the binary mixture ethanol + mesitylene 


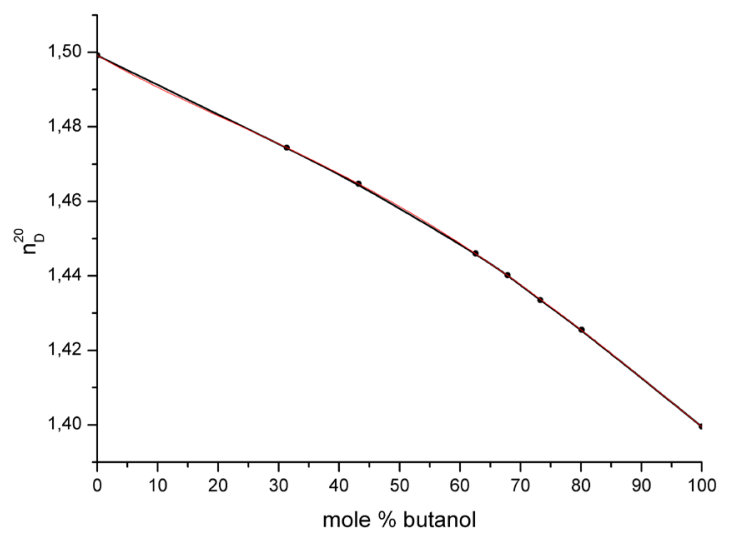

Fig. 3 Variation of refractive index with the composition (as mole \% n-butanol) used as calibration curve for the binary mixture n-butanol + mesitylene

$$
\begin{aligned}
n= & 1.49921-4.39947 \cdot 10^{-4} \cdot z-1.08597 \cdot 10^{-5} \cdot z^{2} \\
& +1.02748 \cdot 10^{-7} \cdot z^{3}-8.69504 \cdot 10^{-1} \cdot z^{4}
\end{aligned}
$$

The correlation between composition and refractive index for the mixture butanol + mesitylene was established in a similar way. The variation of the of $n_{D}^{20}$ with composition for the mixture $n$-butanol + mesitylene is described by the Eq. (2). The $R_{a d j}^{2}$ was in this case $R_{a d j}^{2}=0.99997$. $n=1.4992-9.31514 \cdot 10^{-4} \cdot z+9.10588 \cdot 10^{-6} \cdot z^{2}$

$-1.70535 \cdot 10^{-7} \cdot z^{3}-7.29354 \cdot 10^{-10} \cdot z^{4}$

For both Eq. (1) and Eq. (2), the term $n$ refers to the refractive index of the mixture, while $z$ refers to the composition of the mixture, expressed as mole percent of ethanol, respectively mole percent of butanol.

The results of vapor-liquid measurements are tabulated in Table 3 (ethanol + mesitylene) and Table 4 (n-butanol + mesitylene). The activity coefficients $\gamma_{1}$ and $\gamma_{2}$ calculated starting from the experimental data by using Eq. (3) and Eq. (4) are also displayed. The Antoine coefficients [32] necessary for vapor pressure calculations are shown in Table 5.

$\gamma_{1}=\frac{P y_{1}}{P_{1} x_{1}}$

$\gamma_{2}=\frac{P\left(1-y_{1}\right)}{P_{2}\left(1-x_{1}\right)}$

Where: $P$ - experimental pressure; $P_{1}$ and $P_{2}$ - vapor pressure of component 1 , respectively of component 2 , calculated with Antoine equation; $x_{1}$ and $y_{1}-$ liquid and vapor composition, respectively, expressed as alcohol mole fraction.

The variation of activity coefficients for the studied binaries is displayed in Fig. 4 and Fig. 5. These plots can be used for the evaluation of the thermodynamic consistency of the experimental data.
Table 3 Experimental (vapor + liquid) equilibrium data for temperature $T$, pressure $P$, liquid-phase mole fraction $x$ and vapor phase mole fraction $y$, for the system ethanol (1) + mesitylene (2)

\begin{tabular}{lccccc}
\hline$T / \mathrm{K}$ & $P / \mathrm{kPa}$ & $x_{1}$ & $y_{1}$ & $\gamma_{1}$ & $\gamma_{2}$ \\
\hline 434.84 & 93.42 & 0 & 0 & - & 0.997 \\
381.35 & 93.42 & 0.0268 & 0.8142 & 9.516 & 0.980 \\
373.70 & 93.42 & 0.0738 & 0.8775 & 4.821 & 0.899 \\
365.55 & 93.41 & 0.1275 & 0.8833 & 3.747 & 1.245 \\
356.55 & 93.39 & 0.2050 & 0.9112 & 3.362 & 1.501 \\
355.55 & 93.34 & 0.2652 & 0.9273 & 2.747 & 1.387 \\
352.55 & 93.33 & 0.6016 & 0.9454 & 1.388 & 2.184 \\
351.35 & 93.33 & 0.7947 & 0.9671 & 1.127 & 2.690 \\
350.17 & 93.39 & 0.9152 & 0.9804 & 1.040 & 4.089 \\
349.38 & 93.33 & 1 & 1 & 1.002 & - \\
\hline a uncertainties: $u(T)=0.03 \mathrm{~K}, u(P)=0.01 \mathrm{kPa}, u\left(x_{1}\right)=u\left(y_{1}\right)=0.0001$
\end{tabular}

Table 4 Experimental (vapor + liquid) equilibrium data for temperature

$T$, pressure $P$, liquid-phase mole fraction $x$ and vapor phase mole fraction $y$, for the system butanol (1) + mesitylene (2) ${ }^{\mathrm{b}}$

\begin{tabular}{lccccc}
\hline$T / \mathrm{K}$ & $P / \mathrm{kPa}$ & $x_{1}$ & $y_{1}$ & $\gamma_{1}$ & $\gamma_{2}$ \\
\hline 434.84 & 93.35 & 0 & 0 & - & 0.997 \\
412.55 & 93.31 & 0.0655 & 0.5248 & 3.576 & 0.943 \\
404.88 & 93.35 & 0.1671 & 0.6335 & 2.159 & 1.031 \\
399.15 & 93.35 & 0.2494 & 0.7134 & 1.970 & 1.072 \\
395.15 & 93.28 & 0.3806 & 0.7833 & 1.624 & 1.117 \\
392.87 & 93.37 & 0.5402 & 0.8033 & 1.272 & 1.475 \\
390.35 & 93.39 & 0.7302 & 0.8196 & 1.050 & 2.509 \\
389.55 & 93.31 & 0.7681 & 0.8501 & 1.065 & 2.490 \\
388.65 & 93.28 & 0.8705 & 0.8828 & 1.007 & 3.594 \\
388.77 & 93.39 & 1 & 1 & 1.027 & - \\
\hline${ }^{\mathrm{r}}$ uncertainties: $u(T)=0.03 \mathrm{~K}, u(P)=0.01 \mathrm{kPa}, u\left(x_{1}\right)=u\left(y_{1}\right)=0.0002$
\end{tabular}

Table 5 Antoine coefficients used in the calculation of vapor pressure of the components, with Antoine equation ${ }^{\mathrm{c}}$ [32]

\begin{tabular}{lccc}
\hline & $A_{i}$ & $B_{i}$ & $C_{i}$ \\
\hline Ethanol & 18.9119 & 3803.98 & -41.68 \\
N-butanol & 17.2160 & 3137.02 & -94.34 \\
Mesitylene & 16.2893 & 3614.19 & -63.57 \\
\hline
\end{tabular}

c Antoine equation $\ln P_{i}=A_{i}-\frac{B_{i}}{C_{i}+T}$, with $P_{i}$ in $\mathrm{mmHg}$ and $T$ in $\mathrm{K}$

\section{Binary interaction parameters for NRTL and UNIQUAC models and data correlation}

The vapor-liquid equilibrium data obtained were regressed in PRO/II 9.3 in order to obtain the binary interaction parameters of the NRTL and UNIQUAC thermodynamic models, specific to the studied binary mixtures.

The NRTL model with 5, 8, 10 and 14 binary interaction parameters were considered for regression of the equilibrium 


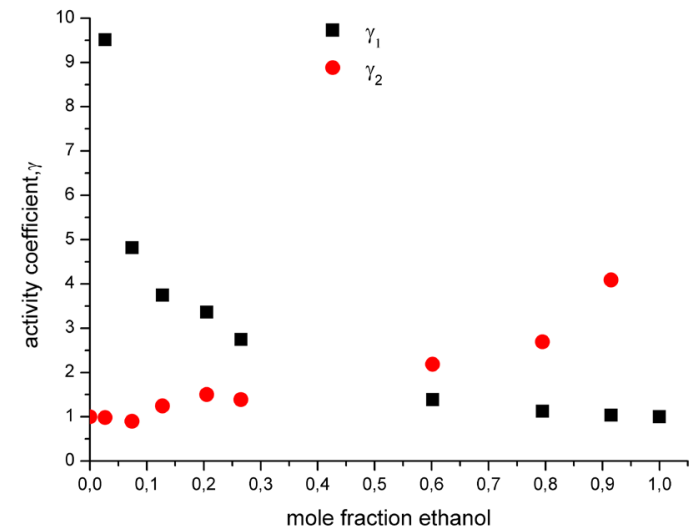

Fig. 4 The variation of activity coefficient $\gamma$ with the molar composition of the liquid phase, for the binary mixture ethanol (1) + mesitylene (2)

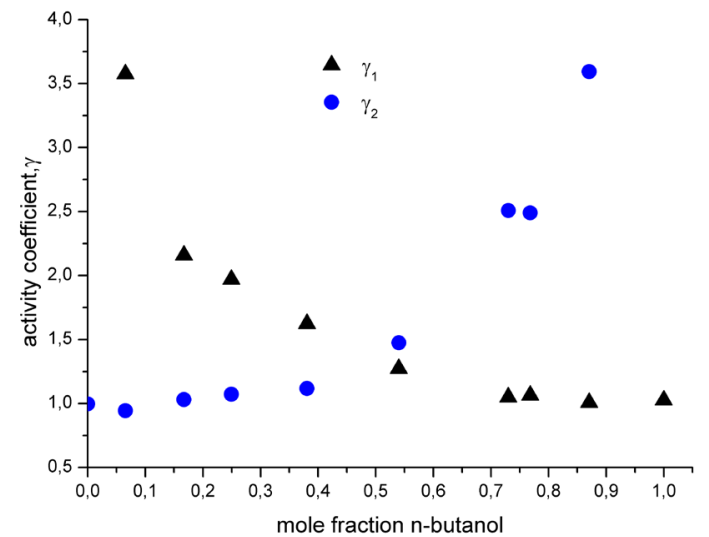

Fig. 5 The variation of activity coefficient $\gamma$ with the molar composition of the liquid phase, for the binary mixture butanol (1) + mesitylene (2)

data. Only the NRTL with 8 binary interaction parameters gave satisfying results in terms of deviation of the calculated parameters (pressure and compositions) from those determined experimentally, for both studied binaries.

NRTL thermodynamic model with 8 binary interaction parameters $[33,34]$ can be described through Eq. (5) - (9):

$\ln \gamma_{i}=\frac{\sum_{i} \tau_{j i} G_{j i} x_{j i}}{\sum_{i} G_{k i} x_{k}}+\sum_{j} \frac{x_{j} G_{i j}}{\sum G_{k j} x_{k}}\left(\tau_{i j}-\frac{\sum_{k} x_{k} \tau_{k j} G_{k j}}{\sum_{k} G_{k j} x_{k}}\right)$

$\tau_{i j}=a_{i j}+\frac{b_{i j}}{T}+\frac{c_{i j}}{T^{2}}$ (unit is $\left.\mathrm{K}\right)$

$\tau_{i j}=a_{i j}+\frac{b_{i j}}{R T}+\frac{c_{i j}}{R^{2} T^{2}}$ (unit is kcal or $\mathrm{kJ}$ )

$G_{i j}=\exp \left(-\alpha_{j i} \tau_{i j}\right)$

$\alpha_{j i}=\alpha_{j i}^{\prime}+\beta_{j i}^{\prime} T$
The results of the regression with NRTL thermodynamic model expressed as relative deviations of the calculated quantities from the experimental measured quantities, are displayed in Table 6, Fig. 6 and Fig. 7.

The maximum relative deviations and the average relative deviation (calculated as $\frac{1}{n} \sum_{i=1}^{n=8} \frac{\left|y_{\text {exp } t}-y_{\text {calc }}\right|}{y_{\text {calc }}} \cdot 100$ ) for: pressure, and composition of the vapor phase are displayed in Table 6. The maximum relative deviations of pressure in case of the ethanol + mesitylene binary mixture is negative and near to $-20 \%$, while for the mixture butanol + mesitylene the maximum relative deviation is $10.12 \%$. The average deviation for pressure does not exceed $8 \%$. The average deviation for vapor composition does not exceed $6 \%$.

Table 6 The maximum relative deviation and the average relative
deviation of pressure and molar composition of the vapor phase,
for the binary mixtures ethanol + mesitylene and n-butanol +
mesitylene, for the regression with NRTL model

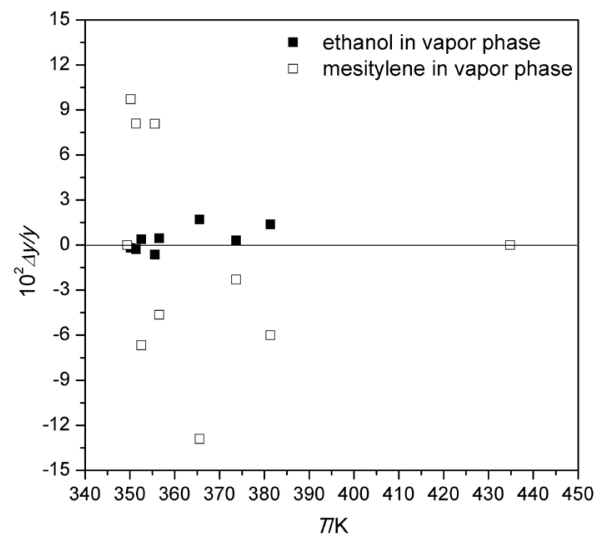

Fig. 6 Relative differences $\Delta y / y=\left(y_{\text {expt }}-y_{\text {calc }}\right) / y_{\text {calc }}$ of the experimental vapor composition $y_{\text {expt }}$, expressed as mole fraction, from those calculated with NRTL model, $y_{\text {calc }}$, for the binary mixture ethanol (1) + mesitylene (2) 


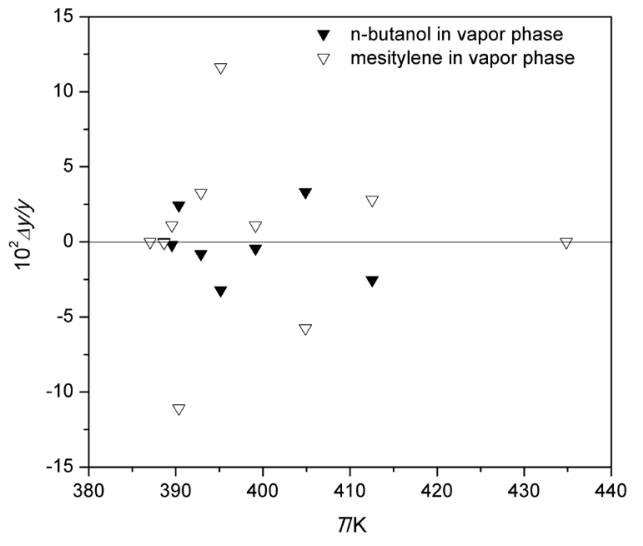

Fig. 7 Relative differences $\Delta y / y=\left(y_{\text {expt }}-y_{\text {calc }}\right) / y_{\text {calc }}$ of the experimental vapor composition $y_{\text {expt }}$, expressed as mole fraction, from those calculated with NRTL model, $y_{\text {calc }}$, for the binary mixture n-butanol (1) + mesitylene (2)

The deviations of the compositions in the vapor phase, calculated during regression of the experimental data with NRTL model for both studied binaries are shown in Fig. 6 (for the binary ethanol + mesitylene) and Fig. 7 (for the binary n-butanol + mesitylene).

The UNIQUAC model with 2 and with 4 binary interaction parameters was tested for the regression of the equilibrium data for the two studied mixture. Better results in terms of deviations of the measured quantities from the calculated ones were obtained with UNIQUAC with 4 binary interaction parameters. Equations (10) - (18) describe the UNIQUAC model [35] with 4 binary interaction parameters:

$\ln \gamma_{i}=\ln \gamma_{i}^{(c)}+\ln \gamma_{i}^{(r)}$

$\ln \gamma_{i}^{(r)}=-q_{i} \ln \left(\sum_{j} \theta_{j} \tau_{j i}\right)+q_{i}-q_{i} \sum_{j} \frac{\theta_{j} \tau_{i j}}{\sum_{k} \theta_{k} \tau_{k j}}$

$\ln \gamma_{i}^{(c)}=\ln \frac{\varphi_{i}}{x_{i}}+\frac{z}{2} q_{i} \ln \frac{\theta_{i}}{\varphi_{i}}+l_{i}-\frac{\varphi_{i}}{x_{i}} \sum_{j} x_{j} l_{j}$

$l_{j}=\frac{z}{2}\left(r_{j}-q_{j}\right)-\left(r_{j}-1\right)$

$\theta_{i}=\frac{q_{i} x_{i}}{\sum_{j} q_{j} x_{j}}$

$\varphi_{i}=\frac{r_{i} x_{i}}{\sum_{j} r_{j} x_{j}}$

$\tau_{i j}=\exp \left(-\frac{U_{i j}}{T}\right)$ when unit is $\mathrm{K}$ $\tau_{i j}=\exp \left(-\frac{U_{i j}}{R T}\right)$ when unit is kcal or $\mathrm{kJ}$

$U_{i j}=a_{i j}+b_{i j} T$.

The deviations of the vapor composition, calculated during the regression of the experimental data with the UNIQUAC thermodynamic model, are displayed in Fig. 8 and Fig. 9.

The relative deviations of the composition in the vapor phase for the binary n-butanol + mesitylene, calculated with UNIQUAC model, are displayed in Fig. 9. It can be observed that similarly to the binary ethanol + mesitylene (Fig. 8), the relative deviations of the concentration of the alcohol (n-butanol) in the vapor phase are smaller than $2.5 \%$.

The relative deviations of the vapor phase composition for the mixture n-butanol + mesitylene, calculated during regression with the UNIQUAC thermodynamic model are

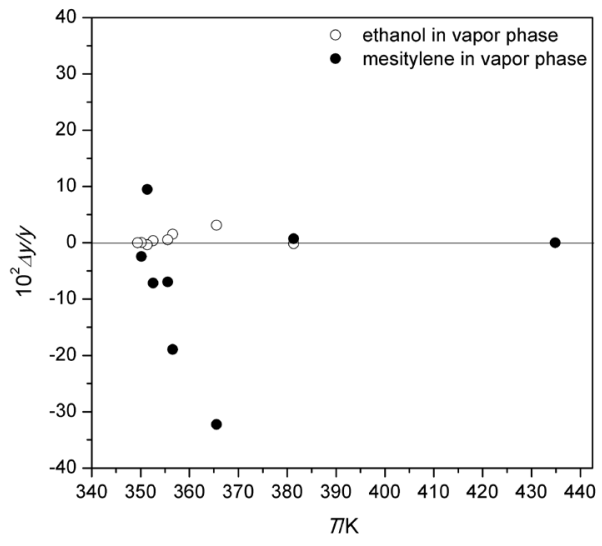

Fig. 8 Relative differences $\Delta y / y=\left(y_{\text {expt }}-y_{\text {calc }}\right) / y_{\text {calc }}$ of the experimental vapor composition $y_{\text {expt }}$ expressed as mole fraction, from those calculated with UNIQUAC model, $y_{\text {calc }}$, for the binary mixture ethanol (1) + mesitylene (2).

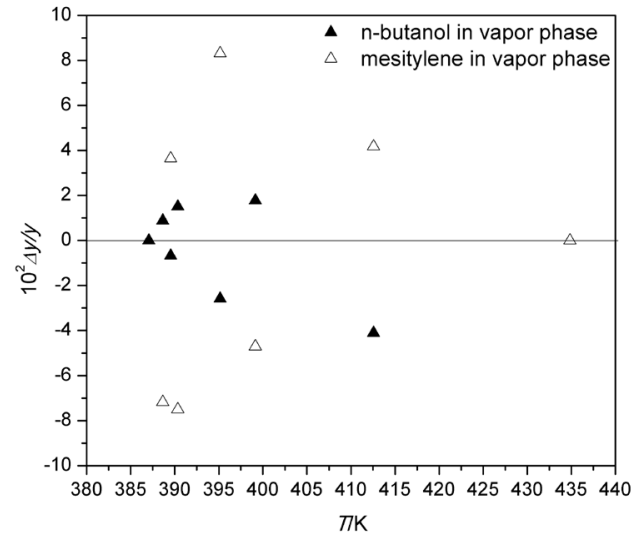

Fig. 9 Relative differences $\Delta y / y=\left(y_{\text {expt }}-y_{\text {calc }}\right) / y_{\text {calc }}$ of the experimental vapor composition $y_{\text {expt }}$ expressed as mole fraction, from those calculated with UNIQUAC model, $y_{\text {calc }}$, for the binary mixture n-butanol (1) + mesitylene (2) 
displayed in Fig. 9. For this mixture, the relative deviations of the concentrations of the components are smaller than in the case of ethanol + mesitylene. The relative deviations of the concentrations of $n$-butanol are situated between $-4 \%-+2 \%$ and the relative deviations of the concentrations of mesitylene are situated in the interval $-8 \%-+8 \%$.

The maximum deviation and average absolute deviation (calculated as $\frac{1}{n} \sum_{i=1}^{n=8}\left|y_{\exp t}-y_{\text {calc }}\right|$ ) of the molar concentrations of ethanol and butanol in the vapor phase, for the fitted models are also presented in Table 7.

The binary interaction parameters of the NRTL thermodynamic model with 8 binary interaction parameters and of the UNIQUAC thermodynamic model with 4 binary interaction parameters, resulted from the regression of the experimental data, for both studied binaries, are presented in Table 8.

The $T-x-y$ diagrams for each binary were generated using the thermodynamic models NRTL and UNIQUAC completed with the binary interaction parameters determined from regression. They were plotted in the same graph with the $T-x-y$ diagram generated with the predictive model UNIFAC [36], and with the experimental points. The comparative $T-x-y$ diagrams for the ethanol +

Table 7 Maximum deviations and average absolute deviations of the molar concentrations of ethanol and butanol in the vapor phase $\left(y_{1}\right)$ for NRTL and UNIQUAC models

\begin{tabular}{lcccc}
\hline & \multicolumn{2}{c}{ NRTL } & \multicolumn{2}{c}{ UNIQUAC } \\
Binary & $\begin{array}{c}\text { Maximum } \\
\text { deviation }\end{array}$ & $\begin{array}{l}\text { Average } \\
\text { absolute } \\
\text { deviation }\end{array}$ & $\begin{array}{c}\text { Maximum } \\
\text { deviation }\end{array}$ & $\begin{array}{l}\text { Average } \\
\text { absolute } \\
\text { deviation }\end{array}$ \\
\hline $\begin{array}{l}\text { Ethanol + } \\
\text { mesitylene }\end{array}$ & 0.0151 & 0.0047 & 0.0034 & 0.0104 \\
$\begin{array}{l}\text { Butanol }+ \\
\text { mesitylene }\end{array}$ & -0.0252 & 0.0091 & 0.0207 & 0.0098 \\
\hline
\end{tabular}

Table 8 Binary interaction parameters of NRTL and UNIQUAC thermodynamic models

\begin{tabular}{lcccc}
\hline \multirow{2}{*}{ Parameter } & \multicolumn{2}{c}{ NRTL model } & \multicolumn{2}{c}{ UNIQUAC model } \\
& $\begin{array}{c}\text { Ethanol }+ \\
\text { mesitylene }\end{array}$ & $\begin{array}{c}\text { Butanol }+ \\
\text { mesitylene }\end{array}$ & $\begin{array}{c}\text { Ethanol }+ \\
\text { mesitylene }\end{array}$ & $\begin{array}{c}\text { Butanol + } \\
\text { mesitylene }\end{array}$ \\
\hline$a_{i j}$ & 0.89569 & 0.95119 & 637.2529 & 2189.006 \\
$b_{i j}$ & 68.492 & 73.257 & -2.117807 & -5.842757 \\
$c_{i j}$ & -53739 & -73059 & - & - \\
$a_{j i}$ & -1.7566 & -4.4103 & -2604.021 & -2713.483 \\
$b_{j i}$ & 174.05 & 71.264 & 8.729953 & 7.800027 \\
$c_{j i}$ & $2.2010 \times 10^{5}$ & $7.3122 \times 10^{5}$ & - & - \\
$\alpha_{i j}$ & 1 & 0.9 & - & - \\
$\beta_{i j}$ & -0.0072298 & -0.00526 & - & - \\
\hline
\end{tabular}

mesitylene mixture can be observed in Fig. 10, and for the mixture n-butanol + mesitylene they can be seen in Fig. 11.

Fig. 10 shows that the experimental points corresponding to the molar composition of the liquid phase are closer to the composition of the liquid phase calculated with the UNIQUAC model, while the experimental points corresponding to the molar composition of the vapor phase are closer to the composition calculated with UNIQUAC and UNIFAC models. All the diagrams displayed in Fig. 10 show a non-ideal system.

Fig. 11 shows comparatively the $T-x-y$ diagrams for the binary mixture n-butanol + mesitylene, calculated with UNIQUAC, NRTL and UNIFAC models, and the experimental points.

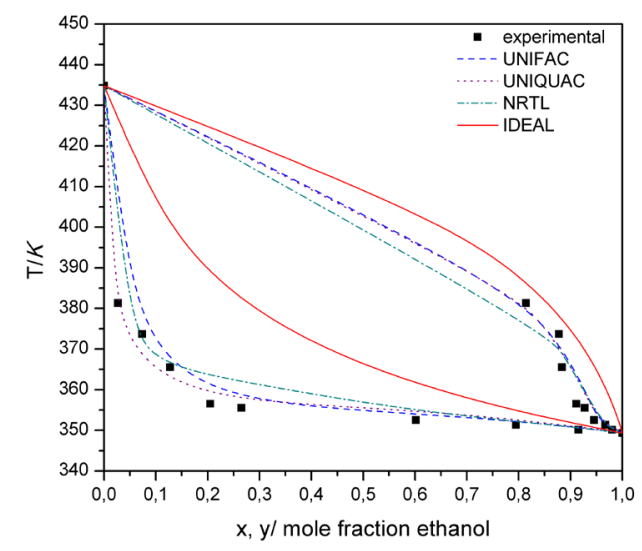

Fig. 10 Comparative $T-x-y$ diagram for the binary mixture ethanol + mesitylene: full square - experimental points; dash line - calculated with UNIFAC predictive model; dot line - calculated with UNIQUAC model; dash dot line - calculated with NRTL model; continuous line calculated with IDEAL model

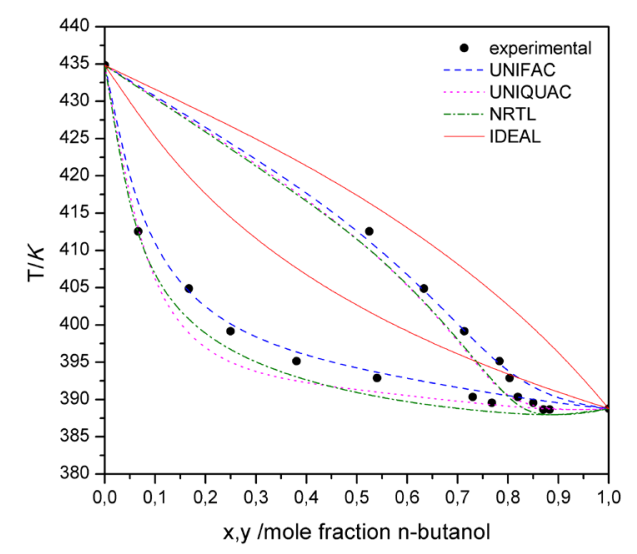

Fig. 11 Comparative $T-x-y$ diagram for the binary mixture n-butanol + mesitylene: full circle - experimental points; dash line - calculated with UNIFAC predictive model; dot line - calculated with UNIQUAC model; dash dot line - calculated with NRTL model; continuous line calculated with IDEAL model 
Observing the shape of the curves, it can be concluded that the mixture n-butanol + mesitylene is a strongly nonideal system which tends to form an azeotrope with high concentration of n-butanol at the experimental pressure of $93.33 \mathrm{kPa}$.

The relative volatility $\left(\alpha_{1 / 2}\right)$ for the studied binaries was calculated with Eq. (19) starting from experimental compositions and from the compositions calculated with the NRTL and UNIQUAC thermodynamic models.

$\alpha_{1 / 2}=\frac{y_{1}\left(1-x_{1}\right)}{x_{1}\left(1-y_{1}\right)}$

The results are displayed in Fig. 12 for the binary ethanol (1) + mesitylene (2) and in Fig. 13 for the binary n-butanol (1) + mesitylene (2).

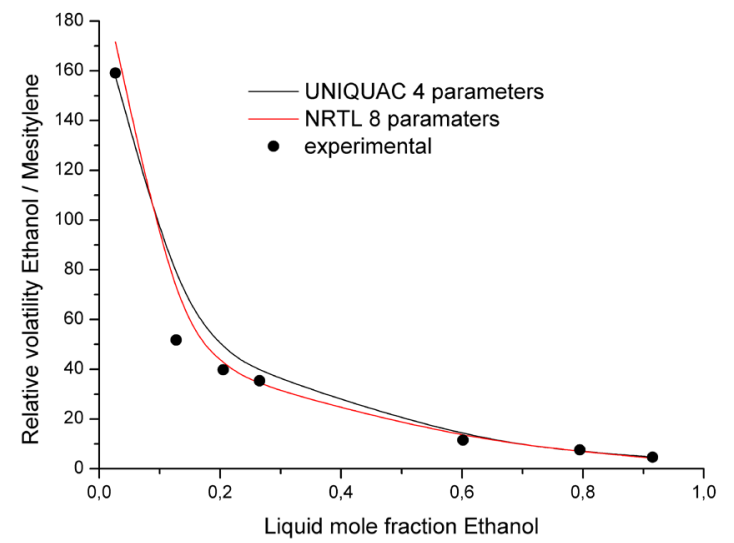

Fig. 12 Comparative relative volatilities for the mixture ethanol + mesitylene, calculated from experimental data (symbol) and with the NRTL model (red line) and UNIQUAC model (black line)

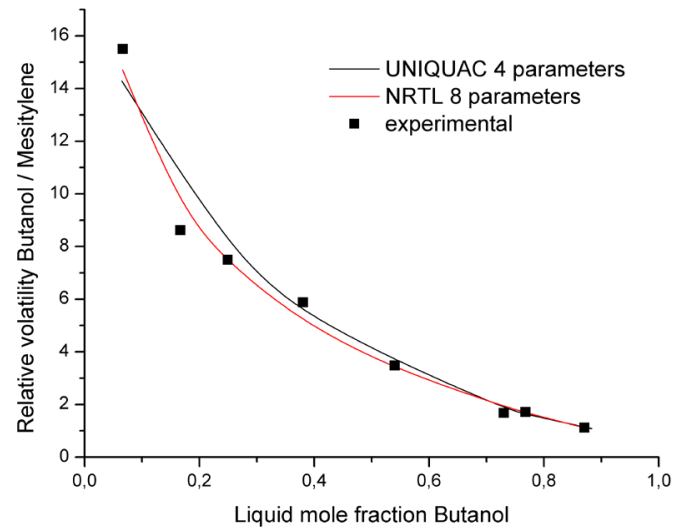

Fig. 13 Comparative relative volatilities for the mixture n-butanol + mesitylene, calculated from experimental data (symbol) and with the NRTL model (red line) and UNIQUAC model (black line)
In Fig. 12 is displayed the variation of the relative volatility for the ethanol-mesitylene binary. The absolute deviation of the volatility calculated with NRTL and UNIQUAC models from the volatility calculated with the experimental data is situated under $10 \%$.

Fig. 13 displays the variation of the relative volatility for the n-butanol-mesitylene binary. The absolute deviation of the volatility calculated with NRTL and UNIQUAC models from the volatility calculated with experimental data is situated under $8 \%$.

\section{Conclusions}

The paper approaches the vapor-liquid equilibrium for two binary mixtures: ethanol + mesitylene and butanol + mesitylene. The $P-T-x-y$ data for the binary mixtures was determined at constant pressure with a double phase circulation apparatus from Normag. The samples taken during the experiments were analyzed by the refractive index method. The binary interaction parameters of the NRTL and UNIQUAC thermodynamic models, specific to the studied binaries, were found by regressing the experimental using PRO/II 9.3 software.

The NRTL and UNIQUAC models with regressed binary interaction parameters were used to calculate the $T-x-y$ diagram at a constant pressure of $93.33 \mathrm{kPa}$. The $T-x-y$ diagram was plotted for each binary as experimental values, values calculated with the NRTL and UNIQUAC models, and the values predicted with the UNIFAC model. All diagrams show that both binaries have a strongly non-ideal behavior. In particular, the binary n-butanol + mesitylene shows large relative volatilities at low alcohol mole fraction, while the relative volatility approaches 1 at alcohol mole fraction exceeding 0.9. Thus, when mesitylene is used as solvent in the ABE process, it is easy to recover the butanol from the butanol-mesitylene extract. However, obtaining high-purity, solvent-free butanol appears to be a difficult task.

\section{Acknowledgement}

The financial support of the European Commission through the European Regional Development Fund and of the Romanian state budget, under the Grant Agreement 155/25.11.2016 (Project POC P-37-449, acronym ASPiRE) is gratefully acknowledged. 


\section{References}

[1] Durre, P. "Biobutanol: an attractive biofuel", Biotechnology Journal, 2(12), pp. 1525-1534, 2007.

https://doi.org/10.1002/biot.200700168

[2] Harvey, B. G., Meylemans, H. A. "The role of butanol in the development of sustainable fuel technologies", Journal of Chemical Technology and Biotechnology, 86(1), pp. 2-9, 2011. https://doi.org/10.1002/jctb.2540

[3] Abdehagh, N., Handan Tezel, F., Thibault, J. "Separation techniques in butanol production: Challenges and developments", Biomass and Bioenergy, 60, pp. 222-246, 2014.

https://doi.org/10.1016/j.biombioe.2013.10.003

[4] Tracy, B. P., Jones. S. W., Fast, A. G., Indurthi, D. C., Papoutsakis, E. T. "Clostridia: the importance of their exceptional substrate and metabolite diversity for biofuel and biorefinery applications", Current Opinion in Biotechnology, 23(3), pp. 364-381, 2012.

https://doi.org/10.1016/j.copbio.2011.10.008

[5] Qureshi, N., Saha, B. C., Dien, B., Hector, R. E., Cotta, M. A. "Production of butanol (a biofuel) from agricultural residues: Part I - Use of barley straw hydrolysate", Biomass and Bioenergy, 34(4), pp. 559-565, 2010

https://doi.org/10.1016/j.biombioe.2009.12.024

[6] Tashiro, Y., Takeda, K., Kobayashi, G., Sonomoto, K., Ishizaki, A., Yoshino, S. "High butanol production by Clostridium saccharoperbutylacetonicum $\mathrm{N} 1-4$ in fed-batch culture with $\mathrm{pH}-\mathrm{Stat}$ continuous butyric acid and glucose feeding method", Journal of Bioscience and Bioengineering, 98(4), pp. 263-268, 2004.

https://doi.org/10.1016/S1389-1723(04)00279-8

[7] Liew, S. T., Arbakariya, A., Rosfarizan, M., Raha, A. R. "Production of Solvent (acetone- butanol- ethanol) in Continuous Fermentation by Clostridium saccharobutylicum DSM 13864 Using Gelatinised Sago Starch as a Carbon Source", Malaysian Journal of Microbiology, 2(2), pp. 42-50, 2006.

https://doi.org/10.21161/mjm.220608

[8] Kraemer, K., Harwardt, A., Bronneberg, R., Marquardt, W. "Separation of butanol from acetone-butanol-ethanol fermentation by a hybrid extraction-distillation process", Computers \& Chemical Engineering, 35(5), pp. 949-963, 2011.

https://doi.org/10.1016/j.compchemeng.2011.01.028

[9] Ezeji, T. C., Qureshi, N., Blaschek, H. P. "Production of acetone, butanol and ethanol by Clostridium beijerinckii $\mathrm{BA}_{101}$ and in situ recovery by gas stripping", World Journal of Microbiology and Biotechnology, 19(6), pp. 595-603, 2003.

https://doi.org/10.1023/A:1025103011923

[10] Ezeji, T. C., Qureshi, N., Blaschek, H. P. "Acetone butanol ethanol (ABE) production from concentrated substrate: reduction in substrate inhibition by fed-batch technique and product inhibition by gas stripping", Applied Microbiology and Biotechnology, 63(6), pp. 653-658, 2004.

https://doi.org/10.1007/s00253-003-1400-x

[11] Ezeji, T. C., Qureshi, N., Blaschek, H. P. "Microbial production of a biofuel (acetone-butanol-ethanol) in a continuous bioreactor: impact of bleed and simultaneous product removal", Bioprocess and Biosystems Engineering, 36(1), pp. 109-116, 2013.

https://doi.org/10.1007/s00449-012-0766-5
[12] Ennis, B. M., Marshall, C. T., Maddox, I. S., Paterson A. H. J. "Continuous product recovery by in-situ gas stripping/condensation during solvent production from whey permeate using Clostridium acetobutylicum", Biotechnology Letters, 8(10), pp. 725-730, 1986. https://doi.org/10.1007/BF01032571

[13] Mollah, A. H., Stuckey, D. C. "Feasibility of in situ gas stripping for continuous acetone-butanol fermentation by Clostridium acetobutylicum", Enzyme and Microbial Technology, 15(3), pp. 200-207, 1993.

https://doi.org/10.1016/0141-0229(93)90138-R

[14] Wang, Y., Chung, T. S., Wang, H., Goh, S. H. "Butanol isomer separation using polyamide-imide/CD mixed matrix membranes via pervaporation", Chemical Engineering Science, 64(24), pp. 5198-5209, 2009. https://doi.org/10.1016/j.ces.2009.08.034

[15] Li, S.-Y., Srivastava, R., Parnas, R. S. "Separation of 1-butanol by pervaporation using a novel tri-layer PDMS composite membrane", Journal of Membrane Science, 363(1-2), pp. 287-294, 2010. https://doi.org/10.1016/j.memsci.2010.07.042

[16] Qureshi, N., Meagher, M. M., Hutkins, R. W. "Recovery of butanol from model solutions and fermentation broth using a silicalite/ silicone membrane", Journal of Membrane Science, 158(1-2), pp. $115-125,1999$. https://doi.org/10.1016/S0376-7388(99)00010-1

[17] Lipnizki, F., Hausmanns, S., Laufenberg, G., Field, R., Kunz, B., "Use of pervaporation-bioreactor hybrid processes in biotechnology", Chemical Engineering Technology, 23(7), pp. 569-577, 2000. https://doi.org/10.1002/1521-4125(200007)23:7<569::AIDCEAT569>3.0.CO;2-1

[18] Regdon, I., Dékány, I., Lagaly, G. "A new way for calculating the adsorption capacity from surface excess isotherms", Colloid and Polymer Science, 276(6), pp. 511-517, 1998. https://doi.org/10.1007/s003960050273

[19] Lin, X., Wu, J., Fan, J., Qian, W., Zhou, X., Qian, C, Jin, X., Wang, L., Bai, J., Ying, H. "Adsorption of butanol from aqueous solution onto a new type of macroporous adsorption resin: Studies of adsorption isotherms and kinetics simulation", Journal of Chemical Technology and Biotechnology, 87(7), pp. 924-931, 2012. https://doi.org/10.1002/jctb.3701

[20] Saravanan, V., Waijers, D. A., Ziari, M., Noordermeer, M. A. "Recovery of 1-butanol from aqueous solutions using zeolite ZSM-5 with a high Si/Al ratio; suitability of a column process for industrial applications", Biochemical Engineering Journal, 49(1), pp. 33-39, 2010. https://doi.org/10.1016/j.bej.2009.11.008

[21] Barton, W. E., Daugulis, A. J. "Evaluation of solvents for extractive butanol, fermentation with Clostridium acetobutylicum and the use of poly(propylene glycol) 1200", Applied Microbiology and Biotechnology, 36(5), pp. 632-639, 1992. https://doi.org/10.1007/BF00183241

[22] Groot, W. J., Soedjak, H. S., Donck, P. B., van der Lans R. G. J. M., Luyben, K. C. A. M., Timmer, J. M. K. "Butanol recovery from fermentations by liquid-liquid extraction and membrane solvent extraction", Bioprocess Engineering, 5(5), pp. 203-216, 1990. https://doi.org/10.1007/BF00376227 
[23] Dadgar, A. M., Foutch, G. L. "Evaluation of solvents for the recovery of Clostridium fermentation products by liquid-liquid extraction", In: Seventh Symposium on Biotechnology for Fuels and Chemicals, Biotechnology and Bioengineering Symposium No. 15, Gatlinburg, TN, USA, 1985, pp. 611-620.

[24] Evans, P. J., Wang, H. Y. "Enhancement of Butanol Formation by Clostridium acetobutylicum in the Presence of DecanolOleyl Alcohol Mixed Extractants", Applied and Environmental Microbiology, 54(7), pp. 1662-1667, 1988.

[25] Patraşcu, I., Bîldea, C. S., Kiss, A. A. "Eco-efficient butanol separation in the ABE fermentation process", Separation and Purification Technology, 177, pp. 49-61, 2017. https://doi.org/10.1016/j.seppur.2016.12.008

[26] Kraemer, K., Harwardt, A., Bronneberg, R., Marquardt, W. "Separation of butanol from acetone-butanol-ethanol fermentation by a hybrid extraction-distillation process", Computers \& Chemical Engineering, 35(5), pp. 949-963, 2011. https://doi.org/10.1016/j.compchemeng.2011.01.028

[27] Verma, R., Dehury, P., Bharti, A., Banerjee, T. "Liquid-liquid extraction, COSMO-SAC predictions and process flow sheeting of 1-butanol enhancement using mesitylene and oleyl alcohol", Journal of Molecular Liquids, 265, pp. 824-839, 2018. https://doi.org/10.1016/j.molliq.2018.06.088

[28] Kurkijärvi, A., Lehtonen, J., Linnekoski, J. "Novel dual extraction process for acetone-butanol-ethanol fermentation", Separation and Purification Technology, 124, pp. 18-25, 2014. https://doi.org/10.1016/j.seppur.2014.01.007

[29] Royal Society of Chemistry "Ethanol Properties: Experimental Refraction Index, on ChemSpider: Search and share chemistry", [online] Available at: http://www.chemspider.com/ChemicalStructure.682.html?rid=4f348923-d8f7-4795-a78d-cf3961e72cc6\&page_num $=0$ [Accessed: 27 January 2019]
[30] Royal Society of Chemistry "n-Butanol Properties: Experimental Refraction Index on ChemSpider: Search and share chemistry", [online] Available at: http://www.chemspider.com/ChemicalStructure. $258 . h t m 1$ ?rid=8a15e5f3-2d17-488b-84f6-c0981db1fc5c [Accessed: 27 January 2019]

[31] Royal Society of Chemistry "Mesitylene Properties: Experimental Refraction Index on ChemSpider: Search and share chemistry", [online] Available at: http://www.chemspider.com/ChemicalStructure. 7659 .html?rid=8d48e4da-3e26-4fba-b4a2-f4616elc82c6 [Accessed: 27 January 2019]

[32] Reid, R. C., Prausnitz, J. M., Poling, B. E. "The properties of gases and liquids", 4th ed., McGraw-Hill, Inc., New York, USA, 1987.

[33] Renon, H., Prausnitz, J. M. "Local compositions in thermodynamic excess functions for liquid mixtures", AIChE Journal, 14(1), pp. 135-144, 1968. https://doi.org/10.1002/aic.690140124

[34] Renon, H., Prausnitz, J. M. "Estimation of Parameters for the NRTL Equation for Excess Gibbs Energies of Strongly Nonideal Liquid Mixtures", Industrial \& Engineering Chemistry Process Design and Development, 8(3), pp. 413-419, 1969. https://doi.org/10.1021/i260031a019

[35] Abrams, D. S., Prausnitz, J. M. "Statistical thermodynamics of liquid mixtures: A new expression for the excess Gibbs energy of partly or completely miscible systems", AIChE Journal, 21(1), pp. 116-128, 1975. https://doi.org/10.1002/aic.690210115

[36] Fredenslund, A., Jones, R. L., Prausnitz, J. M. "Group-contribution estimation of activity coefficients in nonideal liquid mixtures", AIChE Journal, 21(6), pp. 1086-1099, 1975. https://doi.org/10.1002/aic.690210607 